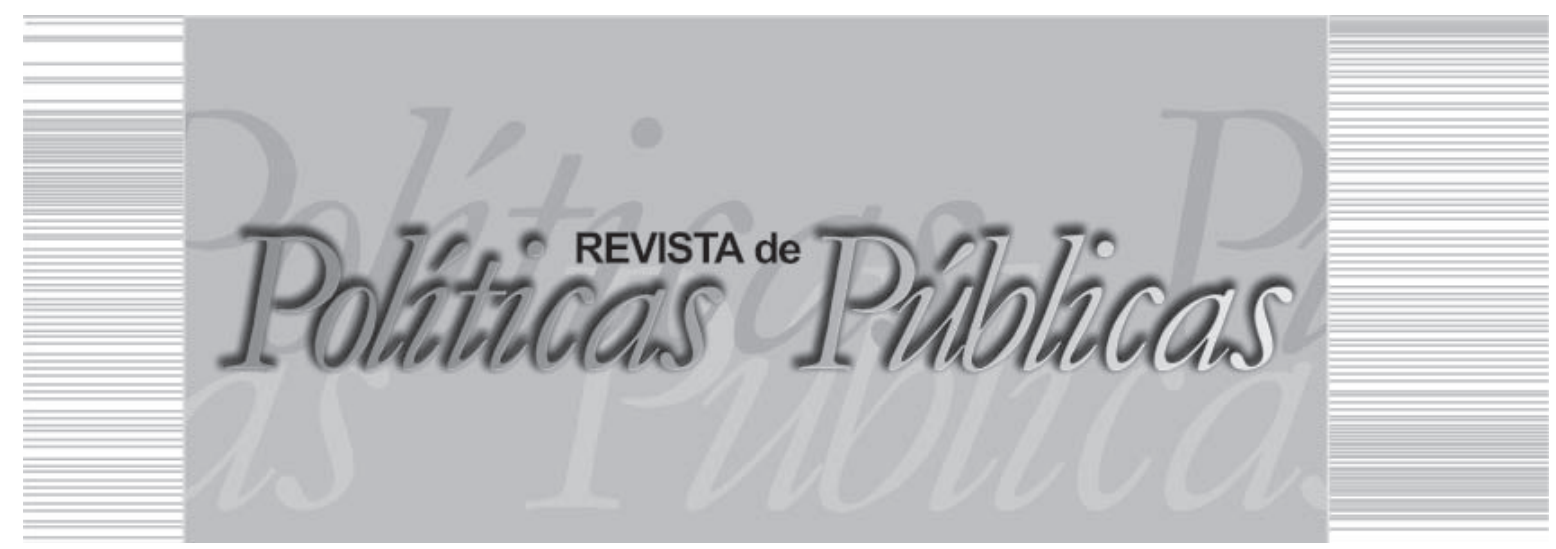

\title{
CAPITAL X TRABALHO: destinação dos recursos tributários do fundo público federal nos governos LULA-DILMA
}

Osmar Gomes Alencar Júnior ${ }^{1}$ Universidade Federal do Piauí (UFPI)

\section{Resumo}

O artigo discute o duplo papel de o fundo público no Estado capitalista contemporâneo reproduzir o capital e a força de trabalho, questionando o destino dos recursos tributários do fundo público federal (FPF) brasileiro. Para tanto, buscou revelar o montante, o destino e a relevância dos gastos social e financeiro nos governos LULA-DILMA, a partir das informações orçamentárias das despesas executadas e pagas pelo governo federal no período de 2003-2014, contidas no SIGA Brasil do Senado Federal. Nos governos de LULA-DILMA mantêm-se os privilégios ao capital, ao passo que são ampliados os salários indiretos da força de trabalho.

Palavras-chave: Fundo Público, orçamento público, gasto social, gasto financeiro.

CAPITAL X WORK: destination of tax resources of the federal public fund in the LULA-DILMA governments

\section{Abstract}

The article discusses the dual role of public fund in the contemporary capitalist state, playing the capital and the labor force, questioning the fate of the tax

\footnotetext{
Economista. Doutorando em Políticas Públicas pela Universidade Federal do Maranhão (UFMA). Professor da Universidade Federal do Piauí (UFPI) - Campus Ministro Reis Velloso. E-mail: jrosmar@hotmail.com | Universidade Federal do Piauí - UFPI - Campus Ministro Reis Velloso -Av. São Sebastião, 2819 - São Benedito, Parnaíba - PI | CEP: 64202-020
} 
resources of the Brazilian federal public fund (FPF). Therefore sought to reveal the amount, the destiny and the relevance of the social and financial costs in the LULA-DILMA governments from the budget information expenditure executed and paid by the federal government in the 2003-2014 period contained in SIGA Brazil's Federal Senate. In the LULA-DILMA governments remain the privileges to capital, while are magnified indirect wages of the workforce. Key words: Public Fund, public budget, social spending, financial spent.

\section{INTRODUÇÃO}

No capitalismo contemporâneo, principalmente nos países latino-americanos, a disputa por recursos do fundo público entre as classes sociais e suas frações,a partir da crise capitalista dos anos 1970/80, passou a ser cada vez mais acirrada. De um lado o capitalista, em especial, o financeiro, pressionando o Estado para direcionar os recursos do orçamento público à reprodução do capital via gastos financeiros e, do outro lado, o trabalhador lutando pela efetivação de direitos sociais, através da ampliação dos gastos sociais.

A disputa pela direção do gasto no interior do fundo público evidencia as prioridades do Estado na aplicação do recurso público. Nesse sentido, o artigo propõe revelar, de forma crítica, a direção do gasto orçamentário no Brasil, no período de 2003 a 2014. A análise crítica dos gastos orçamentários pretende responder ao seguinte questionamento: qual o montante, o destino e a relevância do gasto social e do gasto financeiro no Brasil de LULA-DILMA? E tem como objetivo revelar para onde foram destinados os recursos tributários do Fundo Público Federal (FPF) nos governos LULA-DILMA.

Para tanto, se buscou informações na base de dados do Senado Federal, no sistema de informações orçamentárias SIGA Brasil, onde foram coletadas, organizadas e analisadas as despesas executadas pagas pela União no orçamento federal de 2003-2014. Os valores nominais disponíveis da execução orçamentária federal no SIGA Brasil foram deflacionados pelo Índice Geral de Preços - Disponibilidade Interna (IGP-DI) da Fundação Getúlio Vargas (FGV), tendo como ano base 2014. Por questões metodológicas, os valores referentes ao refinanciamento da dívida pública interna e externa não foram contabilizados nas despesas financeiras, como também foram excluídos da receita orçamentária da União em cada ano analisado, pois estas contas não geraram desembolsos e nem recebimentos efetivos ao governo federal, pelo contrário, é um artifício contábil para 
registrar no orçamento federal a promessa de futuros pagamentos e recebimentos.

O texto está organizado em duas seções, além desta introdução e das considerações finais. A primeira seção trata do fundo público, evidenciando o seu duplo papel no capitalismo, servir ao capital e ao trabalho, e do seu instrumento concreto, o orçamento público. A segunda apresenta a classificação e os determinantes do gasto público no Brasil, revelando qual foi a destinação dos recursos tributários federais no período de 2003-2014.

\section{FUNDO PÚBLICO E ORÇAMENTO PÚBLICO NO CAPITALISMO CONTEMPORÂNEO}

Desde o surgimento, na era absolutista, e até o presente, o Estado moderno nunca parou de expandir sua intervenção na economia e na vida social. Mesmo que em determinadas épocas históricas esse crescimento fosse contestado por economistas liberais como Adam Smith, Jean-Baptiste Say e David Ricardo, pois acreditavam que a intervenção do Estado na economia era perversa, improdutiva, levaria a desequilíbrios orçamentários, salvo raríssimas exceções, reduzindo o ímpeto da reprodução e da acumulação capitalistas. (SANTOS, 2001).

A crise capitalista dos anos 1930 sepultou, por algumas décadas, o protagonismo das ideias liberais de redução do tamanho do Estado e promoveram a ascensão das ideias keynesianas, onde a participação do Estado através da política fiscal expansiva era fundamental para incrementar a demanda efetiva e salvar o sistema da derrocada. O Estado, "[...] de lá para cá, aumentou consideravelmente seu poder de extração de receitas da renda e da riqueza geradas nas economias em geral." (OLIVEIRA, 2012, p. 21).

Ainda para o autor,

O Estado não parou de avançar e de se consolidar como instrumento de organização da sociedade e de garantia da reprodução do sistema, criando as condições necessárias para tanto, mesmo quando retornaram revigoradas, nas últimas décadas do século XX, as vozes que se opõem à sua presença na economia. (OLIVEIRA, 2012, p. 22).

Portanto, dos anos 1930 até o final dos anos 1960, com as reformas keynesianas nos países desenvolvidos, o gasto público es- 
tatal passou a ocupar papel preponderante na resolução dos conflitos econômicos e sociais produzidos pelo modo de produção capitalista. Mesmo diante a crise capitalista dos anos 1970 e o soerguimento das ideias neoliberais de redução do tamanho do Estado, os gastos públicos, em relação ao Produto Interno Bruto (PIB) e à carga tributária, aumentaram nos países membros da Organização para Cooperação Econômica e Desenvolvimento (OCDE). O gasto público médio nos países membros era $36,7 \%$ do PIB (1978-1981) e passou para $41 \%$ (1992-1995). A carga tributária era 34\% do PIB no primeiro período e passou para 37\% no segundo (OLIVEIRA, 2012).

Essa crescente expansão intervencionista do Estado, longe de ser um obstáculo à acumulação, é funcional ao capitalismo, segundo autores de tradição marxista como James O'Connor e Claus Offe. Para o primeiro, o Estado capitalista busca desempenhar duas funções básicas e contraditórias: acumulação e legitimação. "[...] o Estado deve tentar manter, ou criar, as condições em que se faça possível uma lucrativa acumulação do capital. Entretanto, o Estado também deve manter ou criar condições de harmonia social." (O'CONNOR, 1977, p. 19). As duas funções se efetivam através dos gastos estatais e são elementos necessários à acumulação capitalista. Para o segundo, em qualquer fase do desenvolvimento capitalista o Estado estará "[...] funcionalmente relacionado e dependente do processo de acumulação capitalista." (OFFE, 1979, p. 125).

Ora, os aumentos dos gastos públicos e das fontes de recursos tributárias nos países desenvolvidos e em desenvolvimento demonstraram a importância que o fundo público passou a ter na "[...] distribuição dessa expressiva - e crescente - parte da riqueza que é apropriada pelo Estado, mediante tributação, entre as classes, frações de classes, regiões e setores da sociedade." (OLIVEIRA, 2012, p. 122).

O fundo público no capitalismo contemporâneo passou a assumir cada vez mais importância e está presente na reprodução do capital e da força de trabalho das seguintes maneiras, conforme Salvador (2010): a) como fonte importante para a realização do investimento capitalista, por meio de subsídios, de desonerações tributárias, por incentivos fiscais e pela redução da base tributária da renda do capital; b) viabilizando a reprodução da força de trabalho, por meio de salários indiretos, reduzindo custo do capitalista na sua aquisição; c) assegurando recursos orçamentários para investimentos em meios de transporte e infraestrutura, nos gastos com inves- 
tigação e pesquisa, além dos subsídios e renúncias fiscais para as empresas; e, d) transferindo recursos sob a forma de juros e amortização da dívida pública para o capital financeiro, em especial para a classe dos rentistas.

De forma, que o fundo público envolve toda a capacidade de mobilização de recursos que o Estado tem para intervir na economia, seja por meio das empresas públicas, pelo uso das suas políticas monetária e fiscal, assim como pelo orçamento público. (SALVADOR, 2012).

Para Behring (2010, p. 20), o fundo público se forma por meio de uma "[...] punção compulsória - na forma de impostos, contribuições e taxas - da mais-valia socialmente produzida, ou seja, é parte do trabalho excedente que metamorfoseou em lucro, juro ou renda da terra e que é apropriado pelo Estado para o desempenho de suas múltiplas funções." Como também se forma a partir do trabalho necessário, na medida em que os trabalhadores pagam impostos diretos, sobre a renda e o patrimônio e, indiretos, sobre o consumo de mercadorias.

Portanto, o fundo público participa diretamente do processo de reprodução capitalista, seja através dos recursos advindos da exploração do trabalho na produção, seja através dos recursos da exploração tributária crescente em tempos de crise, e constitui-se causa contrariante à queda tendencial da taxa de lucros.

Entretanto, o instrumento mais objetivo do fundo público é o orçamento público; mais do que uma peça técnica de planejamento, é uma arena de disputa política, na qual o direcionamento dos gastos e suas respectivas fontes de financiamentos refletirão, mais que uma decisão econômica, as correlações de forças sociais e políticas hegemônicas na sociedade.

[...] o orçamento deve ser visto como o espelho da vida política de
uma sociedade, à medida que registra e revela, em sua estrutura
de gastos e receitas, sobre que classe ou fração de classe recai o
maior ou o menor onus da tributação e as que mais se beneficiam
com os seus gastos (OLIVEIRA apud SALVADOR; TEIXEIRA,
2014, p. 17)

No sentido lato, o orçamento público pode ser definido como "[...] instrumento de que dispõe o poder público (em qualquer de suas esferas) para expressar, seu programa de atuação, discriminando a origem e o montante dos recursos a serem obtidos, bem como 
a natureza e o montante dos dispêndios." (PISCITELI; TIMBÓ; ROSA, 2006, p. 2). Ainda segundo Oliveira (2012), é através dele que o poder executivo busca cumprir seus programas de governo ou atingir os objetivos macroeconômicos. A definição do programa a ser implantado e a direção da política econômica e social priorizada pelo Estado é reflexo dos interesses de classes, que serão negociados pelos representantes políticos da população, no qual o orçamento é o espaço das suas reivindicações.

No Brasil, a disputa pelo fundo público tem seu acirramento a partir dos anos 1990, em meio ao processo de institucionalização das políticas sociais conquistadas pelos trabalhadores e as frações menos favorecidas, na Constituição de 1988, que clamaram pelo seu financiamento e, ao protagonismo das ideias neoliberais, no interior da burocracia estatal e da classe capitalista, que reivindicavam o ajuste estrutural do Estado, priorizando o financiamento do capital de acordo com os postulados do Consenso de Washington.

Aquele Estado intervencionista/desenvolvimentista na vida econômica e social dos anos 1950/60/70, que atuou "[...] como condutor, organizador e agente estruturante desse processo, com forte atuação na constituição de suas bases, por meio das empresas estatais, dos investimentos públicos e da implementação de políticas voltadas para estimular o //investimento privado." (OLIVEIRA, 2012, p. 75) dá sinais de esgotamento, muito influenciado pela crise da dívida dos anos 1980, e abre espaço para o ideário neoliberal de redução do tamanho do Estado e ampliação da soberania do mercado a partir dos anos 1990.

Ainda segundo o autor,

É este novo Estado, modificado em sua ossatura material, em suas instituições e em seus objetivos-alvo, que, aderindo ao ideário dessa doutrina, os governos Collor (1990-1992) e Fernando Henrique Cardoso (1995-2002) dariam início tanto à construção como ao fortalecimento de suas bases, com a adoção de políticas de abertura comercial e financeira, de desregulamentação da economia e de desmonte do setor público e das políticas sociais, de modo geral, privatizando empresas estatais e promovendo/reduzindo o compromisso do Estado com a oferta de políticas públicas, em prol das forças de mercado, ao mesmo tempo que encaminharam uma série de reformas para realizar seu ajustamento financeiro e assegurar uma gestão responsável de suas finanças, traduzida em equilíbrio 
fiscal e garantia de sustentabilidade e pagamento da dívida pública e de seus encargos. (OLIVEIRA 2012, p. 76).

No governo de Fernando Henrique Cardoso (FHC), mesmo com todo o ajuste fiscal, foi o período em que a dívida pública brasileira explodiu, tanto que a carga tributária atingiu de forma inédita $35 \%$ do PIB, por um lado, nítido passo no sentido de retirar do Estado sua função legitimadora e, por outro, de exacerbar sua função acumulação. Essa preferência pela acumulação trouxe consequências drásticas para a alocação e destinação dos recursos do fundo público, como por exemplo, um aprofundamento do caráter regressivo da carga tributária combinado com um direcionamento maior dos gastos públicos da união para os gastos financeiros, em detrimento dos gastos sociais. E isto não mudou no governo Lula, que, pelo contrário, "[...] deu continuidade ao caráter regressivo do financiamento das políticas de seguridade social do governo anterior, onerando fiscalmente os trabalhadores e as classes de menores rendas e privilegiando os capitalistas, principalmente, os da fração superior das classes capitalistas." (ALENCAR JÚNIOR; SALVADOR, 2015, p. 247), acontecendo o mesmo no governo Dilma.

3 GASTOS PÚBLICOS NO BRASIL: alocação dos recursos tributários do Fundo Público Federal (FPF) no período de 2003-2014

Para Riani (2009, p. 54), os gastos públicos são escolhas políticas dos governos no que se refere aos diversos serviços prestados à sociedade. Representa "[...] o custo da provisão dos bens e serviços executados pelo setor público que aparece nas contas orçamentárias do governo." Para o autor, essa categoria ultrapassa o conceito de gastos governamentais, despesas realizadas em unidades da administração direta e indireta do governo (incluso as autarquias e fundações), acrescentando as despesas com as atividades econômicas produtivas (empresas estatais).

Baleeiro (apud OLIVEIRA, 2012, p. 123) reforça que os gastos públicos são fruto de decisões políticas, pois "[...] em todos os tempos e lugares, a escolha da despesa envolve um ato político, que também se funda em critérios políticos, isto é, nas ideias, convicções e interesses revelados nos entrechoques dos grupos detentores do poder." Para Oliveira (2012, p. 122), 
[...] a estrutura da despesa governamental deve revelar, em cada realidade e em cada contexto histórico, as forças econômicas e políticas que, com maior poder de influência sobre as decisões de gasto do Estado - ou seja, as que determinam sua direção e tendências -, conseguem acomodar, no orçamento, seus interesses.

Entretanto, para maior transparência da despesa pública, existem várias formas de classificação do gasto no orçamento público. Para Giacomoni (2010), a despesa pode ser classificada de forma institucional, funcional, por programas e segundo a natureza. A primeira tem por finalidade essencial "[...] evidenciar as unidades administrativas responsáveis pela execução da despesa, isto é, os órgãos que gastam os recursos de conformidade com a programação orçamentária." (GIACOMONI, 2010, p. 90).

A segunda tem como objetivo principal "[...] fornecer as bases para a apresentação de dados e estatísticas sobre os gastos públicos nos principais segmentos em que atuam as organizações do Estado." (GIACOMONI, 2010, p. 95). Tem como critério funcional de classificação as categorias função (o maior nível de agregação da despesa pública) e subfunção (parte da função e um subconjunto da despesa pública).

A terceira busca "[...] demonstrar as realizações do governo, o resultado final de seu trabalho em prol da sociedade." (GIACOMONI, 2010, p. 100). E por último, a classificação segundo a natureza tem como finalidade evidenciar os efeitos do gasto público sobre a economia.

As despesas da União também podem ser classificadas em financeiras e não financeiras. A primeira diz respeito aos gastos do governo federal com o financiamento da reprodução do capital, na forma de pagamentos de juros e amortizações, isto é, pagamentos dos serviços da dívida pública (interna e externa) brasileira, bem como seu refinanciamento. Para efeito deste estudo, excluir-se-ão os valores do refinanciamento da dívida pública interna e externa do total das despesas financeiras

E a segunda são os gastos do governo federal com o custeio da máquina pública, com a reprodução da força de trabalho, na forma de salários indiretos pagos pelo Estado aos trabalhadores, na forma de gastos com a ordem social (Assistência Social, Previdência Social, Saúde, Educação, Cultura, Direitos da Cidadania, Gestão Ambiental, Ciência e Tecnologia, Comunicações e Desporto e La- 
zer) e do capital, na forma de despesas de investimentos, em meios de transporte e infraestrutura, nos gastos com investigação e pesquisa, além dos subsídios e renúncias fiscais para as empresas.

Ora, se o orçamento é uma arena de disputa política capitaneada pelo Estado, onde as classes sociais e suas frações mais poderosas, econômica e politicamente, disputam os recursos tributários com as classes menos favorecidas, as quais deveriam ser as principais beneficiadas, qual fora o montante e a destinação dos recursos do orçamento da União nos governos LULA-DILMA?

Em 2003, no primeiro governo do presidente Lula, as despesas financeiras (gastos com juros e amortizações da dívida) da União excluídas os valores do refinanciamento da dívida eram $\mathrm{R} \$$ 157 bilhões e representavam $32 \%$ dos gastos orçamentários. As despesas não financeiras eram $R \$ 336,7$ bilhões e representavam $68 \%$, de acordo com a Tabela 1. Em 2006, no final do primeiro mandato, as despesas financeiras eram $\mathrm{R} \$ 275,4$ bilhões e corresponderam a $36 \%$ dos gastos orçamentários, e as despesas não financeiras eram $\mathrm{R} \$ 496$ bilhões e participaram com 64\%.

Tabela 1 - Gastos com despesas financeiras e não financeiras da União excluídos os valores do refinanciamento da dívida, em R\$ milhões, no período 2003-2014

\begin{tabular}{lcccccccccccc}
\hline $\begin{array}{l}\text { Despesas } \\
\text { Da Uniäo }\end{array}$ & 2003 & 2004 & 2005 & 2006 & 2007 & 2008 & 2009 & 2010 & 2011 & 2012 & 2013 & 2014 \\
$\begin{array}{l}\text { Despesas } \\
\text { Năo }\end{array}$ \\
$\begin{array}{c}\text { Financeiras } \\
\text { Despesas }\end{array}$ & 336.718 & 350.922 & 446.397 & 496.076 & 538.464 & 595.231 & 726.158 & 726.530 & 855.940 & 920.719 & 1.046 .648 & 1.189 .728 \\
\hline $\begin{array}{l}\text { Financeiras } \\
\text { Total }\end{array}$ & 157.022 & 140.914 & 144.672 & 275.427 & 228.001 & 268.751 & 400.166 & 246.440 & 237.332 & 437.514 & 261.717 & 363.043 \\
\hline
\end{tabular}

Fonte: Elaborado pelo autor, conforme dados do SIGA Brasil.

Os primeiros quatro anos do governo Lula evidenciaram um aumento real de $56 \%$ no total das despesas orçamentárias da União, puxado pela taxa de crescimento de $47 \%$ das despesas não financeiras, mas, principalmente, pelo crescimento de $75 \%$ das despesas financeiras.

Nos dois primeiros anos do segundo mandato do presidente Lula as despesas financeiras recuaram a patamares inferiores aos valores de 2006, para depois atingir o teto de $\mathrm{R} \$ 400,1$ bilhões em 2009 e recuar para $\mathrm{R} \$ 246,4$ bilhões no ano de 2010 , como pode ser visualizado no Gráfico 1 . Nesse período as despesas financeiras cresceram apenas $8 \%$ e as despesas não financeiras 35\%. 
Gráfico 1 - Evolução dos gastos da União com as despesas financeiras e não financeiras, excluídas as despesas com o refinanciamento da dívida pública, em $\mathrm{R} \$$ milhões, no período de 2003 a 2014

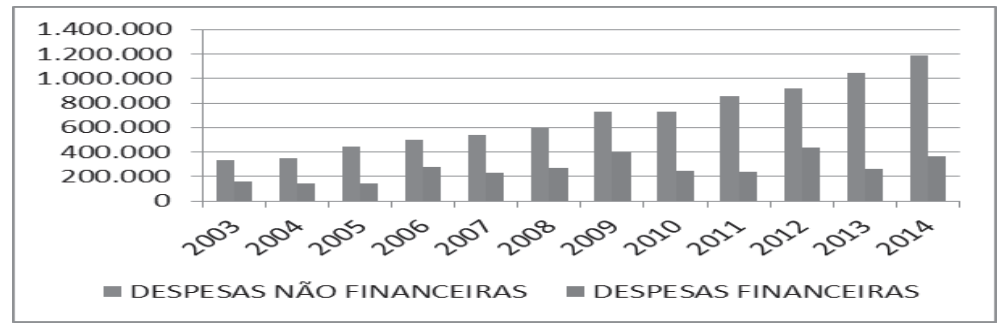

Fonte: Elaborado pelo autor, conforme dados do SIGA Brasil.

Portanto, do ponto de vista dos gastos com despesas financeiras e não financeiras da União no governo Lula (2003-2010), ficou evidente o crescimento real mais acentuado das despesas não financeiras $(116 \%)$ em relação às despesas financeiras $(57 \%)$. Em conseqüência, a participação das despesas financeiras no total das despesas orçamentárias foi reduzida de $32 \%$ em 2003 para $25 \%$ em 2010. No entanto, os gastos financeiros médios de R \$179,5 bilhões no primeiro governo foram elevados para R $\$ 285,8$ bilhões no segundo governo, depois de ter atingido o teto financeiro de $\mathrm{R} \$ 400,1$ bilhões no penúltimo ano de governo.

No governo Dilma as despesas financeiras eram R $\$ 237,3$ bilhões, em 2011, atingiram o teto de $\mathrm{R} \$ 437,5$ bilhões em 2012, recuaram para R \$261,7 bilhões em 2013 e voltaram a crescer para R\$ 363 bilhões em 2014. Enquanto as despesas não financeiras eram R\$ 855,9 bilhões e passaram, respectivamente, para $\mathrm{R} \$ 920,7$ bilhões, R \$ 1 trilhão e R \$ 1,1 trilhão nos anos 2012, 2013 e 2014, como pode ser visto no Gráfico 1.

Os primeiros quatro anos do governo Dilma mostraram um aumento real de $42 \%$ no total das despesas orçamentárias da União, puxado pela taxa de crescimento de $39 \%$ das despesas não financeiras, mas, principalmente, pelo crescimento de $53 \%$ das despesas financeiras. Quanto aos gastos financeiros médios, eles alcançaram $\mathrm{R} \$ 324,9$ bilhões no período, além do que no segundo ano de governo da presidenta os valores gastos nesta rubrica superaram em R\$ 37 bilhões os maiores valores pagos, em 2012, pelo governo Lula.

Portanto, durante os 12 anos de governo do Partido dos Trabalhadores (PT) no Brasil, os gastos reais da União cresceram 214\%, 
influenciados pelo crescimento real de $253 \%$ das despesas não financeiras e $131 \%$ das despesas financeiras. Em média o país destinou por ano R $\$ 685,7$ bilhões para os gastos não financeiros e $\mathrm{R} \$ 263,4$ bilhões para os financeiros.

Entretanto, apenas, parte do gasto não financeiro foi destinada à reprodução da força de trabalho, isto é, a realização de gastos na ordem social brasileira, enquanto a totalidade dos gastos financeiros foi distribuída entre os gastos com os serviços da dívida pública interna e externa.

No primeiro governo Lula os gastos sociais passaram de R\$ 199,2 bilhões em 2003 para R $\$ 292,9$ bilhões em 2006. E os gastos como o serviço da dívida pública federal saltaram de R $\$ 143,7$ bilhões em 2003 para $R \$ 262,4$ bilhões em 2006, como pode ser visto na Tabela 2. O que evidenciou um crescimento real de $47 \%$ nos gastos sociais contra um crescimento de $83 \%$ no pagamento do serviço da dívida pública, puxado por um acréscimo de $112 \%$ nos serviços da dívida interna.

Tabela 2 - Gastos da União com a ordem social e o serviço da dívida pública federal, em R\$ milhões, no período de 2003 a 2014

\begin{tabular}{|c|c|c|c|c|c|c|c|c|c|c|c|c|}
\hline Função & 2003 & 2004 & 2005 & 2006 & 2007 & 2008 & 2009 & 2010 & 2011 & 2012 & 2013 & 2014 \\
\hline $\begin{array}{l}\text { Ordem } \\
\text { Social }\end{array}$ & $\begin{array}{l}\text { 今. } \\
\text { ळे } \\
\text { ळ }\end{array}$ & 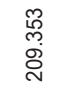 & 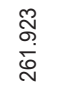 & 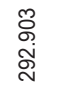 & $\begin{array}{l}\hat{\hat{0}} \\
\stackrel{m}{\hat{m}}\end{array}$ & & 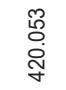 & 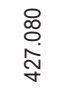 & 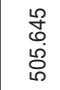 & 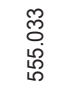 & 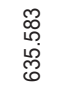 & $\begin{array}{l}\stackrel{8}{8} \\
\infty \\
\infty \\
i\end{array}$ \\
\hline $\begin{array}{c}\text { Serviço } \\
\text { da Dívida } \\
\text { Interna }\end{array}$ & $\begin{array}{l}\text { జ్ } \\
\text { Oें } \\
\stackrel{0}{-}\end{array}$ & 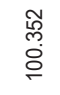 & $\begin{array}{l}\overline{\widehat{\delta}} \\
\stackrel{0}{\rightleftharpoons}\end{array}$ & 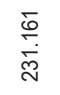 & 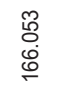 & 边 & & ֻٕ & $\begin{array}{l}\infty \\
\stackrel{\infty}{f} \\
\stackrel{6}{\sim} \\
\stackrel{\omega}{N}\end{array}$ & 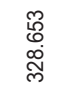 & $\begin{array}{l}0 \\
\infty \\
\infty \\
\text { d } \\
\text { N }\end{array}$ & $\begin{array}{l}\stackrel{\infty}{\infty} \\
\stackrel{\infty}{\circ} \\
\stackrel{\infty}{\sim}\end{array}$ \\
\hline $\begin{array}{c}\text { Serviço } \\
\text { da Divida } \\
\text { Externa }\end{array}$ & 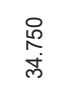 & $\begin{array}{l}\stackrel{\mathscr{p}}{\Gamma} \\
\stackrel{m}{m}\end{array}$ & 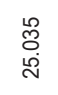 & $\begin{array}{l}\stackrel{\circ}{m} \\
\stackrel{m}{m}\end{array}$ & 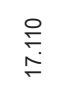 & $\begin{array}{l}\frac{m}{6} \\
\stackrel{m}{\sigma}\end{array}$ & $\begin{array}{l}\stackrel{0}{t} \\
\stackrel{0}{6}\end{array}$ & 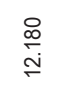 & 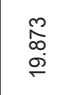 & 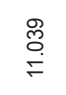 & 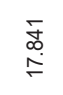 & $\begin{array}{l}\text { Q } \\
\text { ஸे } \\
\text { ஸे }\end{array}$ \\
\hline $\begin{array}{c}\text { Total } \\
\text { Serviço } \\
\text { da Dívida } \\
\text { Pública } \\
\text { Federal }\end{array}$ & 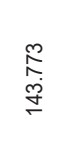 & 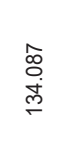 & $\begin{array}{l}\mathscr{8} \\
\mathbb{8} \\
\dot{7} \\
\end{array}$ & 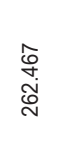 & 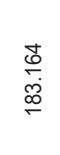 & 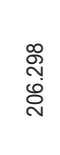 & $\begin{array}{l}D \\
\infty \\
\infty \\
\& \\
\stackrel{o}{N}\end{array}$ & 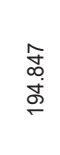 & 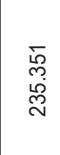 & 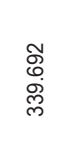 & 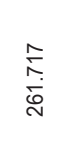 & $\begin{array}{l}\infty \\
o \\
\infty \\
\infty \\
\text { d } \\
\text { d. }\end{array}$ \\
\hline
\end{tabular}

Fonte: Elaboração própria, conforme dados do SIGA Brasil.

No segundo governo Lula, os gastos sociais iniciaram o período com R \$ 312,6 bilhões e fecharam em 2010 atingindo valores da ordem de R $\$ 427$ bilhões. Já os gastos com juros e amortizações da dívida eram R \$ 183,1 bilhões e atingiram R \$ 194,8 bilhões em 2010. 
Um crescimento de $37 \%$ no social e um acréscimo de apenas $6 \%$ nos gastos do serviço da dívida, muito influenciado pela redução de $29 \%$ no pagamento de juros e amortizações da dívida externa.

Portanto, nos oito anos de governo Lula, os gastos sociais cresceram $114 \%$ e as despesas com o serviço da dívida pública federal aumentaram $36 \%$, porém a participação do serviço da dívida pública federal no total do orçamento da União foi reduzida em 31\%.

No governo Dilma os gastos sociais alcançam $\mathrm{R} \$ 505,6$ bilhões em 2011 e atingiram o teto de R \$ 718,9 bilhões em 2014. Já as despesas com o serviço da dívida pública federal passaram de $\mathrm{R} \$$ 235,3 bilhões para $\mathrm{R} \$ 298,4$ bilhões em 2014 . Um crescimento de $42 \%$ dos gastos sociais e um acréscimo de $27 \%$ nas despesas como o serviço da dívida pública.

Os números do orçamento da União no período analisado confirmaram a função dupla do fundo público no Estado capitalista contemporâneo, reproduzir o capital e a força de trabalho através dos gastos estatais, a pender para um dos dois lados, dependendo do momento histórico e dos interesses das forças políticas interclasses, aglutinadas ou não, que disputam politicamente no interior do orçamento a direção e efetivação do gasto público. Nesse sentido, quais interesses políticos prevaleceram na disputa orçamentária pela relevância do gasto social e do gasto financeiro nos governos LULA-DILMA?

A Constituição Federal (CF) de 1988, no Título VIII - Da Ordem Social, Capítulos I ao VIII, assegura que todas as despesas neste campo de atuação (seguridade social; a educação, a cultura e desporto; a ciência e tecnologia; a comunicação social; o meio ambiente; a família, criança, adolescente e idoso e os índios) são gastos sociais e serão financiados pelo Estado brasileiro.

Para demonstrar quais interesses políticos prevaleceram nestes anos de governo do PT, a Tabela 3 mostrará a participação das despesas por função e subfunção no orçamento da União, isto é, evidenciará efetivamente a real direção dos gastos tributários e a relevância dada ao capital na forma de despesas financeiras e ao trabalho via gastos sociais pelos governos de LULA-DILMA na execução orçamentária federal. 
CAPITAL X TRABALHO: destinação dos recursos tributários do fundo público federal nos governos Lula-Dilma

Tabela 3 - Participação das despesas por função e subfunção no orçamento da União, excluídos os valores do refinanciamento da dívida, no período de 2003 - 2014 (\%)

\begin{tabular}{|c|c|c|c|c|c|c|c|c|c|c|c|c|}
\hline Função & 2003 & 2004 & 2005 & 2006 & 2007 & 2008 & 2009 & 2010 & 2011 & 2012 & 2013 & 2014 \\
\hline $\begin{array}{l}08 \text { - Assistencia } \\
\text { Social }\end{array}$ & 1,6 & 2,6 & 2,7 & 2,8 & 3,1 & 3,1 & 3,1 & 3,7 & 4,1 & 3,8 & 4,6 & 4,3 \\
\hline $\begin{array}{l}09 \text { - Previdencia } \\
\text { Social }\end{array}$ & 30,0 & 31,0 & 32,5 & 27,5 & 29,3 & 26,5 & 25,9 & 30,0 & 31,3 & 27,2 & 32,3 & 30,4 \\
\hline 10 - Saúde & 5,3 & 5,7 & 5,8 & 4,7 & 5,0 & 4,9 & 4,6 & 5,3 & 5,8 & 5,0 & 5,8 & 5,6 \\
\hline 12 - Educação & 2,7 & 2,5 & 2,4 & 2,2 & 2,5 & 2,6 & 2,9 & 3,9 & 4,3 & 4,0 & 5,0 & 5,2 \\
\hline 13 - Cultura & 0,0 & 0,0 & 0,1 & 0,1 & 0,1 & 0,1 & 0,1 & 0,1 & 0,1 & 0,1 & 0,1 & 0,1 \\
\hline $\begin{array}{l}14 \text { - Direitos da } \\
\text { Cidadania }\end{array}$ & 0,1 & 0,1 & 0,1 & 0,1 & 0,1 & 0,1 & 0,1 & 0,1 & 0,1 & 0,0 & 0,1 & 0,0 \\
\hline $\begin{array}{l}18 \text { - Gestão } \\
\text { Ambiental }\end{array}$ & 0,1 & 0,2 & 0,2 & 0,2 & 0,2 & 0,2 & 0,2 & 0,2 & 0,2 & 0,2 & 0,3 & 0,2 \\
\hline $\begin{array}{l}19 \text { - Ciência e } \\
\text { Tecnologia }\end{array}$ & 0,3 & 0,4 & 0,5 & 0,4 & 0,4 & 0,4 & 0,4 & 0,5 & 0,4 & 0,4 & 0,5 & 0,4 \\
\hline 24 - Comunicações & 0,1 & 1,3 & 1,3 & 1,1 & 1,0 & 0,9 & 1,0 & 0,9 & 0,9 & 0,7 & 0,7 & 0,7 \\
\hline $\begin{array}{l}27 \text { - Desporto e } \\
\text { Lazer }\end{array}$ & 0,0 & 0,0 & 0,0 & 0,0 & $0,1 \%$ & 0,0 & 0,0 & 0,0 & 0,0 & 0,0 & 0,0 & 0,1 \\
\hline $\begin{array}{l}843 \text { - Serviço da } \\
\text { Dívida Interna }\end{array}$ & 22,1 & 20,4 & 20,2 & 30,0 & 21,7 & 22,3 & 24,9 & 18,8 & 19,7 & 24,2 & 18,6 & 18,6 \\
\hline $\begin{array}{l}844 \text { - Serviço da } \\
\text { Dívida Externa }\end{array}$ & 7,0 & 6,9 & 4,2 & 4,1 & 2,2 & 1,6 & 1,5 & 1,3 & 0,8 & 0,8 & 1,4 & 0,6 \\
\hline $\begin{array}{l}\text { Serviço da Divida } \\
\text { Pública Federal } \\
(843+844)\end{array}$ & 29,1 & 27,3 & 24,5 & 34,0 & 23,9 & 23,9 & 26,4 & 20,0 & 21,5 & 25,0 & 20,0 & 19,2 \\
\hline Ordem Social & 40,4 & 42,6 & 44,3 & 38,0 & 40,8 & 38,0 & 37,3 & 43,9 & 46,3 & 40,9 & 48,6 & 46,3 \\
\hline $\begin{array}{l}\text { (\%) Orçamento } \\
\text { União }\end{array}$ & 69,5 & 69,9 & 68,8 & 72,0 & 64,7 & 61,9 & 63,7 & 63,9 & 67,8 & 65,9 & 68,6 & 65,5 \\
\hline
\end{tabular}

Fonte: Elaboração própria, conforme dados do SIGA Brasil.

Como podem ser visualizados na Tabela 3, 62\%a72\% de todos os recursos orçamentários federais foram direcionados aos gastos sociais e financeiros, nos 12 anos dos governos LULA-DILMA. Os gastos com a ordem social, isto é, com assistência social, previdência social, saúde, educação, cultura, direitos de cidadania, gestão ambiental, ciência e tecnologia, comunicações e desporto e lazer, que beneficiam milhões de trabalhadores, principalmente as frações de renda mais baixa, tiveram uma participação média de $42 \%$ no 
total dos gastos orçamentários federal neste período. Enquanto os gastos com o serviço da dívida pública (interna e externa), que beneficiam poucos, principalmente, a fração dos capitalistas financeiros, participaram com $25 \%$.

No primeiro governo Lula (2003-2006), a participação dos gastos sociais no orçamento da União inicia o período com $40,4 \%$ e finaliza com 38\%, de acordo com a Tabela 3, houve uma redução de $5,9 \%$ na sua participação orçamentária. As áreas sociais mais afetadas foram a educação, com redução de 17,9\%, saúde com 11,3\% e Previdência Social com $8,2 \%$, justamente as três maiores despesas sociais orçamentárias. No entanto outras despesas sociais cresceram sua participação, principalmente, desporto e lazer 248,6\%, assistência social $68,7 \%$, direitos da cidadania $35,8 \%$ e cultura $32 \%$, muito embora esse crescimento exponencial, exceto na segunda, tenha pouca repercussão nas contas do governo, haja vista a pouca expressividade das suas despesas, não compensando as perdas em outras áreas sociais.

Por outro lado, a participação das despesas com o serviço da dívida pública no orçamento total federal cresceu $16,8 \%$, influenciado por uma queda de $42,3 \%$ na participação dos gastos com juros e amortizações da dívida externa e, principalmente, com um acréscimo de $35,7 \%$ no serviço da dívida interna.

No segundo governo Lula (2007-2010), os gastos sociais aumentaram sua participação em $7,6 \%$, influenciados pelo incremento na participação na educação de $55,8 \%$, direitos da cidadania $50,5 \%$, cultura $42,8 \%$, ciência e tecnologia $28,8 \%$, assistência social $20,6 \%$, saúde $5,7 \%$ e previdência social $2,2 \%$. Por outro lado, os gastos financeiros reduziram sua participação em $16,2 \%$, puxados por uma queda, respectivamente, de $43,9 \%$ e $12,9 \%$, nas participações dos serviços da dívida externa e interna.

Portanto, os oito anos do governo Lula são marcados por um primeiro período histórico, em que os interesses do capital na forma de gastos financeiros se sobrepõem aos interesses do trabalho na forma de gastos sociais, e um segundo período, em que o pêndulo pende para os gastos com salários indiretos, via expansão da participação dos gastos sociais em detrimento da redução da participação dos gastos financeiros no orçamento federal.Apesar do pêndulo ora pender para os gastos financeiros, ora pender para os gastos sociais, quando a série histórica é analisada sem frações de períodos, 
percebe-se uma expansão de $8,7 \%$ na participação dos gastos sociais e uma redução de $31,2 \%$ na participação dos gastos financeiros. O que demonstra que o Estado capitalista brasileiro do governo Lula cumpriu sua dupla função, com destaque para a legitimação.

No governo Dilma (2011-2014), a participação dos gastos sociais no orçamento da União não cresceu (estável em 46,3\%), como pode ser visualizado na Tabela 3. As áreas sociais mais afetadas com a redução de gastos foram: direitos da cidadania com $45,2 \%$, ciência e tecnologia $13,4 \%$, saúde $3,6 \%$ e previdência social com $2,9 \%$. No entanto, outras despesas sociais cresceram sua participação, principalmente, desporto e lazer $91,6 \%$, comunicações $32,3 \%$, educação $22,5 \%$ e assistência social $6,2 \%$.

Nesse mesmo período a participação das despesas com o serviço da dívida pública no orçamento federal foi reduzida em 10,7\%, influenciada por reduções de $67,1 \%$ e 5,5\% na participação dos gastos com juros e amortizações da dívida externa e interna, respectivamente.

Portanto, os 12 anos dos governos LULA-DILMA demonstraram que os interesses políticos interclasses em disputa no interior do fundo público, mais precisamente, na sua parte mais objetiva, o orçamento público federal, forjaram um Estado capitalista que ampliou sua presença na sociedade brasileira na forma de serviços ofertados, promovendo um incremento de $14,7 \%$ na participação dos gastos sociais no total dos gastos públicos federais. Muito embora os interesses políticos, contrários à ampliação da presença do Estado e favoráveis ao aumento dos gastos financeiros serem reduzidos em $34 \%$ na sua participação no orçamento federal, a subfunção serviço da dívida pública constituiu-se área das mais relevantes da despesa federal, do ponto de vista do fluxo de recursos tributários destinados a seu pagamento.Uma clara sinalização da importância que os dois governos dispensaram à remuneração do capital financeiro, principalmente ao pagamento da dívida interna.

\section{CONCLUSÃO}

Este artigo demonstrou a disputa pela direção do gasto tributário no interior do fundo público, evidenciando as prioridades do Estado brasileiro na aplicação do recurso público nos governos LULA-DILMA, a partir da análise da execução do orçamento público federal, segundo suas fontes de recursos. E permitiu fazer algumas 
constatações, que podem ser visualizadas vertical e horizontalmente na matriz abaixo: nos governos do PT, a preferência do Estado pela função acumulação é mantida, tanto na manutenção do caráter regressivo da carga tributária, como na apropriação privada cada vez maior dos recursos do fundo público. A diferença está na função de legitimação, que nesses governos é ampliada, principalmente, no segundo governo Lula, único período em que as despesas não financeiras, gastos sociais e a participação dos gastos sociais no orçamento federal cresceram conjuntamente numa proporção mais elevada que os gastos financeiros, como pode ser visto no Quadro 1.

Quadro 1 - Matriz explicativa do montante, direção e relevância dos gastos social e financeiro nos governos LULA-DILMA

\begin{tabular}{|c|c|c|c|c|c|}
\hline Variáveis & $\begin{array}{c}\text { LULA } \\
2003-2006\end{array}$ & $\begin{array}{c}\text { LULA } \\
2007-2010\end{array}$ & $\begin{array}{c}\text { LULA } \\
\text { 2003-2010 }\end{array}$ & $\begin{array}{c}\text { DILMA } \\
2011-2014\end{array}$ & $\begin{array}{l}\text { LULA-DILMA } \\
2003-2014\end{array}$ \\
\hline $\begin{array}{c}\text { Montante } \\
\text { dos gastos } \\
\text { tributários }\end{array}$ & 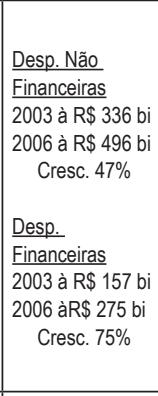 & 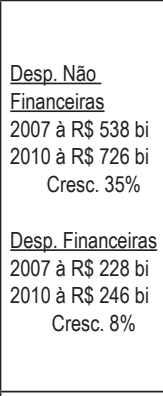 & $\begin{array}{l}\text { Crescimento de } \\
116 \% \text { das desp. } \\
\text { nãofinanceiras } \\
\text { Crescimento de } \\
57 \% \text { das desp. } \\
\text { financeiras }\end{array}$ & 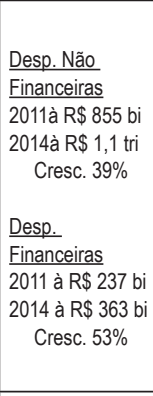 & $\begin{array}{l}\text { - Crescimento de } \\
214 \% \text { nos gastos } \\
\text { da União; } \\
\text { - Crescimento de } \\
253 \% \text { nas desp. } \\
\text { não financeiras; } \\
\text { - Crescimento de } \\
131 \% \text { nas desp. } \\
\text { financeiras; } \\
\text { - Gasto financeiro } \\
\text { médio R\$ } 263 \text { bi; } \\
\text { - Gasto não } \\
\text { financeiro médio } \\
\text { R\$ } 685 \text { bi }\end{array}$ \\
\hline $\begin{array}{l}\text { Direção dos } \\
\text { recursos } \\
\text { tributários }\end{array}$ & $\begin{array}{l}\text { Gastos Sociais } \\
2003 \text { à R\$ } 199 \text { bi } \\
2006 \text { à R\$ } 293 \text { bi } \\
\text { Cresc. } 47 \% \\
\\
\frac{\text { Gastos Serviço }}{\text { Dívida Pública }} \\
2003 \text { à R\$ } 143 \text { bi } \\
2006 \text { à R\$ } 262 \text { bi } \\
\text { Cresc. } 83 \%\end{array}$ & $\begin{array}{c}\frac{\text { Gastos Sociais }}{2007 \text { à } R \$ 312 \text { bi }} 2010 \text { à } R \$ 427 \text { bi } \\
\text { Cresc. } 37 \% \\
\frac{\text { Gastos Serviço }}{\text { Dívida Pública }} \\
2007 \text { à } R \$ 183 \text { bi } \\
2010 \text { à } R \$ 194 \text { bi } \\
\text { Cresc. } 6 \%\end{array}$ & $\begin{array}{l}\text { Crescimento de } \\
114 \% \text { dos gastos } \\
\text { sociais; } \\
\\
\text { Crescimento de } \\
36 \% \text { dos gastos } \\
\text { com o serviço da } \\
\text { dívida pública }\end{array}$ & $\begin{array}{l}\text { Gastos Sociais } \\
\text { 2011à R\$ } 505 \text { bi } \\
\text { 2014à R\$ } 719 \text { bi } \\
\text { Cresc. } 42 \% \\
\\
\text { Gastos Serviço } \\
\text { Dívida Pública } \\
\text { 2011à R\$ } 235 \text { bi } \\
\text { 2014à R\$ } 298 \text { bi } \\
\text { Cresc. } 27 \%\end{array}$ & $\begin{array}{l}\text { Crescimento de } \\
261 \% \text { dos gastos } \\
\text { sociais; } \\
\\
\text { Crescimento de } \\
108 \% \text { dos gastos } \\
\text { com o serviço da } \\
\text { dívida pública }\end{array}$ \\
\hline
\end{tabular}


CAPITAL x TRABALHO: destinação dos recursos tributários do fundo público federal nos governos Lula-Dilma

\begin{tabular}{|c|c|c|c|c|c|}
\hline $\begin{array}{l}\text { Relevância } \\
\text { dos gastos }\end{array}$ & $\begin{array}{l}\frac{\% \text { Gastos Sociais }}{\text { no Orçamento }} \\
\frac{\text { Federal }}{2003 \text { à } 40 \%} \\
2006 \text { à } 38 \% \\
\quad \text { Redução } 6 \% \\
\frac{\% \text { Gastos Serviço }}{2} \\
\frac{\text { Divida Pública }}{\text { no Orçamento }} \\
\frac{\text { Federal }}{2003 \text { à } 29 \%} \\
2006 \text { à 34\% } \\
\text { Cresc. } 17 \%\end{array}$ & 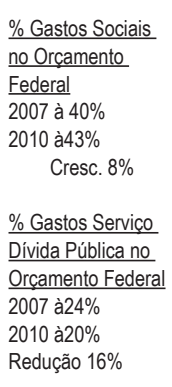 & $\begin{array}{l}\text { Crescimento de } \\
9 \% \text { na participação } \\
\text { dos gastos sociais } \\
\text { no orçamento } \\
\text { federal; } \\
\\
\text { Redução de } 31 \% \\
\text { na participação } \\
\text { dos gastos com } \\
\text { o serviço da } \\
\text { divida pública no } \\
\text { orçamento federal }\end{array}$ & 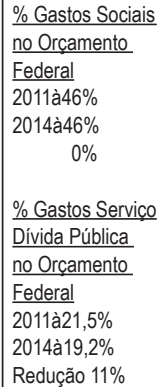 & $\begin{array}{l}\text { Crescimento } \\
\text { de } 15 \% \text { na } \\
\text { participação dos } \\
\text { gastos sociais } \\
\text { no orçamento } \\
\text { federal; } \\
\text { Redução de } 34 \% \\
\text { na participação } \\
\text { dos gastos com } \\
\text { o serviço da } \\
\text { dívida pública } \\
\text { no orçamento } \\
\text { federal }\end{array}$ \\
\hline
\end{tabular}

Fonte: Elaboração própria.

No que diz respeito ao montante dos gastos tributários financeiros e não financeiros, as despesas não financeiras foram as mais representativas. Aportaram R $\$ 685$ bilhões por ano, o que significou uma participação média de $72 \%$ dessa despesa no total dos gastos federais anuais no período de 2003-2014. No entanto, o crescimento mais acelerado das despesas financeiras, em dois, dos três períodos analisados, sinalizaram um maior direcionamento dos recursos tributários para os gastos financeiros no primeiro governo Lula e no governo Dilma.

No que diz respeito à direção dos gastos tributários, os gastos sociais foram os mais representativos. Aportaram R $\$ 405$ bilhões por ano, o que significou uma participação média de $42 \%$ desa despesa no gasto federal anual em doze anos. $\mathrm{E}$ o crescimento mais acelerado no segundo governo Lula e no governo Dilma reforçaram a prevalência do direcionamento dos recursos públicos para esses gastos. Mesmo assim, os gastos financeiros com o serviço da dívida pública foram responsáveis por despesas na ordem de $\mathrm{R} \$ 225$ bilhões por ano, com uma participação média anual de $25 \%$. E no primeiro governo Lula os gastos com os juros e amortizações da dívida pública cresceram numa proporção maior, de quase o dobro, que o crescimento dos gastos sociais.

No que diz respeito à relevância dos gastos, tanto a participação dos gastos sociais, como a das despesas com o serviço da dívida no orçamento federal, não melhoraram. Pelo contrário, foram reduzidas ou mantiveram-se estáveis em quase todo o período analisado.

No governo Lula (2003-2010), apesar do direcionamento dos gastos para as despesas financeiras, na forma de pagamentos dos serviços da dívida pública, no primeiro governo, e para os gastos 
sociais no segundo, houvera, ao longo do período, uma prevalência dos gastos sociais. Estes cresceram $114 \%$ contra $36 \%$ dos gastos com o serviço da dívida pública brasileira.

No governo Dilma (2011-2014), os crescentes incrementos nos gastos sociais e nas despesas financeiras não foram suficientes para melhorar a relevância do gasto social, sua participação no orçamento federal, e muito menos a participação dos gastos com o serviço da dívida pública, que apesar de os pagamentos terem crescido $27 \%$, pioraram $11 \%$.

No governo LULA-DILMA (2003-2014), os gastos da União cresceram $214 \%$, as despesas não financeiras $253 \%$ e as despesas financeiras $131 \%$. Os gastos médios, não financeiro e financeiro, foram R $\$ 685$ bilhões e R $\$ 263$ bilhões, respectivamente. Houve crescimento de $261 \%$ nos gastos sociais e $108 \%$ nas despesas com o serviço da dívida pública, o que possibilitou um incremento de $15 \%$ na participação dos gastos sociais e uma redução de $34 \%$ na participação do serviço da dívida pública no orçamento federal. No entanto, foram transferidos para o sistema financeiro nacional e internacional, na forma de juros e amortizações da dívida pública, mais de $\mathrm{R} \$ 3$ trilhões.

Portanto, este trabalho corroborou vários outros, com a tese do papel duplo de o fundo público no Estado capitalista contemporâneo servir ao capital, na medida em que financia a acumulação capitalista, principalmente, via pagamento da dívida pública e, servir ao trabalho, na medida em que amplia o pagamento de salários indiretos para os trabalhadores via expansão dos gastos sociais.

\section{REFERÊNCIAS}

ALENCAR JÚNIOR, O. G.; SALVADOR, E. Finanças, fundo público e financiamento da seguridade social no Brasil. Revista Katálysis, Florianópolis, v. 18, n. 2, p. 239-248, jul./dez. 2015.

BEHRING, E. R. Crise do capital, fundo público e valor. In:

BOSCHETTI, I. et al. (Orgs). Capitalismo em crise, política social e direitos. São Paulo: Cortez, 2010.

BRASIL. Constituição Federal 1988. 21. ed. Brasília, DF: Câmara dos Deputados, 2003.

GIACOMONI, J. Orçamento público. 15 ed. São Paulo: Atlas, 2010. 
CAPITAL x TRABALHO: destinação dos recursos tributários do fundo público federal nos governos Lula-Dilma

O'CONNOR, J. USA: a crise do Estado capitalista. Rio de Janeiro: Paz e Terra, 1977.

OFFE, C. Estado e capitalismo. Rio de Janeiro: Tempo Brasileiro, 1979.

OLIVEIRA, F. A. de. Economia e política das finanças públicas no Brasil. São Paulo: Hucitec, 2012.

RIANI, F. Economia do setor público: uma abordagem introdutória. Rio de Janeiro: LTC, 2009.

PISCITELI, R.; TIMBÓ, M.; ROSA, M. Contabilidade pública. 9. ed. São Paulo: Atlas, 2006.

SALVADOR, E. Financiamento tributário da política social no pósReal. In: et al. (Org). Financeirização, fundo público e política social. São Paulo: Cortez, 2012.

Fundo público e seguridade social. São Paulo: Cortez, 2010.

; TEIXEIRA, S. O. Orçamento e políticas sociais: metodologia de análise na perspectiva crítica. Revista de Políticas Públicas, São Luís, v. 18, n. 1, p. 15-32, jan./jun. 2014.

SANTOS, R. S. A teoria das finanças públicas no contexto do capitalismo: uma discussão com os filósofos economistas: de Smith a Keynes. São Paulo: Mandacaru; Salvador: CETEAD, 2001 
